\title{
Psychological problems among university students in Saudi Arabia during the COVID-19 pandemic
}

\author{
Zeinab Mohammed ${ }^{1}$, Ahmed Arafa ${ }^{2}$, El-Sayed Atlam ${ }^{3}$, Nader El-Qerafi ${ }^{2}$, Momen \\ El-Shazly ${ }^{4}$, Omar Al-Hazazi ${ }^{2}$, and Ashraf Ewis ${ }^{2}$ \\ ${ }^{1}$ Beni-Suef University \\ ${ }^{2}$ Affiliation not available \\ ${ }^{3}$ Taibah University \\ ${ }^{4}$ Taibah University College of Medicine
}

February 5, 2021

\begin{abstract}
Abstract: Background: The 2019 coronavirus disease (COVID-19) pandemic is a public health emergency and constitutes a challenge to psychological health. This study aimed to assess the psychological conditions among university students in Saudi Arabia during the COVID-19 pandemic. Material and Methods: During the period between the 4th and 18th of June 2020, the students at Umm AlQura University in Saudi Arabia were invited to complete an online survey. The survey assessed their sociodemographic characteristics, educational disciplines, and manifestations of depression, anxiety, and stress as determined by the Depression Anxiety Stress Scale-21 (DASS-21). Results: The study included 936 students. Of them, 41.1\% had depressive symptoms ( $31.7 \%$ mild to moderate and $9.4 \%$ severe to very severe), $26.9 \%$ had anxiety symptoms ( $15.8 \%$ mild to moderate and $11.1 \%$ severe to very severe), and $22.4 \%$ had stress symptoms ( $15.2 \%$ mild to moderate and $7.2 \%$ severe to very severe). Students who reported having a friend or relative infected with or died from COVID-19, watching or reading news about the pandemic [?]2 hours/day, and not having emotional support from family, university, and society were more likely to show psychological problems. Conclusion: Symptoms of depression, anxiety, and stress were common among Saudi university students. Psychological counseling and support should be provided to university students in Saudi Arabia. Keywords: Depression; Anxiety; Stress; COVID-19; University students; Saudi Arabia
\end{abstract}

Title: Psychological problems among the university students in Saudi Arabia during the COVID-19 pandemic

Authors: Zeinab Mohammed ${ }^{1}$, Ahmed Arafa ${ }^{1,2}$, El-Sayed Atlam ${ }^{3,4}$, Nader El-Qerafi ${ }^{5}$, Momen El-Shazly ${ }^{6,7}$, Omar Al-Hazazi ${ }^{8}$, Ashraf Ewis ${ }^{9,10}$

${ }^{1}$ Department of Public Health, Faculty of Medicine, Beni-Suef University, Beni-Suef, Egypt

${ }^{2}$ Department of Public Health, Graduate School of Medicine, Osaka University, Osaka, Japan

${ }^{3}$ Department of computer science, Faculty of Science, Tanta University, Egypt.

${ }^{4}$ Department of computer science, College of Computer Science and Engineering, Taibah University, Yanbu, Saudi Arabia.

${ }^{5}$ Department of Occupational and Environmental Health, Al-Madinah Health Affairs Directorate, AlMadinah Al-Munawwarah, Saudi Arabia

${ }^{6}$ Department of Medicine, Taibah College of Medicine, Taibah University, Al-Madinah Al-Munawwarah, Saudi Arabia 
${ }^{7}$ Department of Occupational Medicine, Faculty of Medicine, Sohag University, Sohag, Egypt

${ }^{8}$ Department of Chemistry, Faculty of Science, Umm AlQura University, Mecca, Saudi Arabia

${ }^{9}$ Department of Public Health and Occupational Medicine, Faculty of Medicine, Minia University, El-Minia, Egypt

${ }^{10}$ Department of Public Health, Faculty of Health Sciences - AlQunfudah, Umm AlQura University, Mecca, Saudi Arabia

\section{Email addresses:}

ZM: zynab.mohammed@med.bsu.edu.eg

AA: ahmed011172@med.bsu.edu.eg

EA: saltam@yahoo.com

NE: ashraf.ewis926@gmail.com

ME: momenhafez79@yahoo.com

OA:oahazazi@uqu.edu.sa

AE: ashraf.ewis926@gmail.com

Corresponding author: Zeinab Mohammed

Department of Public Health, Faculty of Medicine, Beni-Suef University, Beni-Suef, Egypt

E-mail: zynab.mohammed@med.bsu.edu.eg

Disclosure: NO disclosure relevant to this work

Abstract word count: 208, Text word count: 2551,Tables: 3, References : 26

Abstract: Background: The 2019 coronavirus disease (COVID-19) pandemic is a public health emergency and constitutes a challenge to psychological health. This study aimed to assess the psychological conditions among university students in Saudi Arabia during the COVID-19 pandemic.

Material and Methods: During the period between the $4^{\text {th }}$ and $18^{\text {th }}$ of June 2020, the students at Umm AlQura University in Saudi Arabia were invited to complete an online survey. The survey assessed their sociodemographic characteristics, educational disciplines, and manifestations of depression, anxiety, and stress as determined by the Depression Anxiety Stress Scale-21 (DASS-21).

Results: The study included 936 students. Of them, $41.1 \%$ had depressive symptoms $(31.7 \%$ mild to moderate and $9.4 \%$ severe to very severe), $26.9 \%$ had anxiety symptoms (15.8\% mild to moderate and $11.1 \%$ severe to very severe), and $22.4 \%$ had stress symptoms ( $15.2 \%$ mild to moderate and $7.2 \%$ severe to very severe). Students who reported having a friend or relative infected with or died from COVID-19, watching or reading news about the pandemic [?]2 hours/day, and not having emotional support from family, university, and society were more likely to show psychological problems.

Conclusion: Symptoms of depression, anxiety, and stress were common among Saudi university students. Psychological counseling and support should be provided to university students in Saudi Arabia.

Keywords: Depression; Anxiety; Stress; COVID-19; University students; Saudi Arabia

What's known? (what is already known about this subject?)

COVID pandemic has many psychological implications that affected people and communities variously.

What's new? (what does this study contribute to the literature?) 
The psychological impacts of the pandemic on university students was assessed in non arab countries like china however the psychological response of the Saudi Arabia medical students which considered the largest Arab country in the middle east region was not assessed to the best of our knowledge. Understanding how students behave in such emerging situations may help authorities to alleviate the psychological implications on students and younger adults

\section{Introduction:}

The 2019 coronavirus disease (COVID-19) pandemic is a public health emergency that represents a challenge to psychological health (1). Saudi Arabia is among the most affected countries in the Middle East with 229,480 confirmed cases and 2181 related deaths as of the $12^{\text {th }}$ of July 2020 (2). To respond to the COVID19 pandemic, Saudi Arabia has taken preventive precautions including quarantine measures, suspending education at schools and universities before starting distance learning and virtual classrooms later, and closing the mosques including the Holy Mosque of Mecca $(3,4)$

Literature showed that such measures can result in several psychological problems (5), and students, in particular, are more vulnerable (6). In addition, isolation from campus life, the need to adapt to the new online educational environment, and the uncertainty about the academic and occupational future can carry additional burdens (5, 7-9). A study in Jordan, , found that the level of anxiety among university students was higher than in medical professions and the general population (6). Other studies conducted on university students from China and Spain showed varying degrees of psychological problems related to the COVID-19 pandemic $(1,10-13)$

Despite the urgency of this topic worldwide, the psychological problems among university students in Saudi Arabia were not assessed during the COVID-19 pandemic. Determining the psychological impacts of the COVID-19 on university students and the correlating factors can help in initiating risk-prevention procedures and counseling programs to relieve this burden. Herein, we investigated the prevalence of depression, anxiety, and stress among university students in Umm AlQura University in the holy city of Mecca in Saudi Arabia and studied the associating factors

\section{Methods:}

\section{Subjects and study design:}

A Google survey was created and the link to the survey was sent by e-mails to university students at Umm AlQura University in Saudi Arabia. The e-mails were sent on the $4^{\text {th }}$ of June 2020 reminders were sent a week later. We also shared the link to the Google survey to the private social network groups that include social gatherings of Umm AlQura University students. Students were asked to forward the link to their peers from their contact e-mail and social network lists. The last date of data collection was the $18^{\text {th }}$ of June 2020.

\section{Data collection:}

We designed an Arabic questionnaire composed of four sections to collect the data. Section I included a detailed explanation of the steps, aims, and eligibility criteria of the study. Section II included questions about the sociodemographic and educational features of students including age (in years), sex (man or woman), residence (urban or rural area), and discipline (faculty or institute name). Section III had questions related to the COVID-19 pandemic including having a friend or relative infected with COVID-19 (yes, no, or not sure), having a friend or relative died from COVID-19 (yes, no, or not sure), wearing masks (always, sometimes, or never), using detergents (always, sometimes, or never), applying social distancing (always, sometimes, or never), watching/reading COVID-19 news ( $<2,2-4$, or $>4$ hours/day), average daily sleeping hours per day $(<6,6-9$, or $>9$ hours/day), and receiving enough emotional support from the family (yes or no), society (yes or no), and the university (yes or no). Section IV included the Arabic version of the Depression Anxiety Stress Scale-21 (DASS-21). The DASS-21 is a quantitative measure of depression, anxiety, and stress symptomatology (7 statements each) during the past week. The depression statements evaluated hopelessness, dysphoria, self-deprecation, devaluation of life, lack of interest and involvement, anhedonia, and inertia. The anxiety statements evaluated skeletal muscle effects, autonomic arousal, situational anxiety, and subjective 
experience of anxious affect. The stress scale evaluated nervous arousal, difficulties in relaxation, and being easily upset or over-reactive. Students had to decide how much the statements applied for them using a scale from zero to three where zero referred to "did not apply to me at all", one referred to "applied to me to some degree or some of the time", two referred to "applied to me to a considerable degree or a good part of the time" and three referred to "applied to me very much or most of the time". The score of each axis was multiplied by two to lie within a zero to 42 scale where higher scores indicated worse outcomes. The cut-off values for the DASS-21 scales were the following: 1) Depression: normal (0-9), mild to moderate (10-20), and severe to extremely severe ([?]21), 2) Anxiety: normal (0-7), mild to moderate (8-14), and severe to extremely severe ([?]15), and 3) Stress: normal (0-14), mild to moderate (15-25), and severe to extremely severe $([?] 26)(14,15)$. In this study, depression, anxiety, and stress were considered outcomes.

\section{Statistical analyses:}

We used descriptive statistics in the form of percentages to present the sociodemographic and educational characteristics of the students in addition to their prevalence rates of depression, anxiety, and stress during the COVID-19 pandemic. Logistic regression analyses were conducted to determine the associating factors, in the form of odds ratios (ORs) and confidence intervals (CIs), with depression, anxiety, and stress symptoms. The mild to moderate and severe to very severe forms were merged in each psychological condition to obtain statistical power. P-values of less than 0.05 were considered significant. Data were analyzed using the Statistical Package for Social Science (SPSS) released in 2013 (IBM SPSS Statistics for Windows, Version 22.0, IBM Corporation, Armonk, New York).

\section{Ethical considerations:}

We conducted this study in full accordance with the guidelines for Good Clinical Practice and the Declaration of Helsinki. The conditions of the study were described in section I and respondents had to agree to proceed to the upcoming sections and to submit their answers after filling out the survey which was considered approval of participation.

\section{Results:}

Of the 936 Saudi university students who responded to the online questionnaire, $57.8 \%$ were $<23$ years old, $56.4 \%$ were females, $56.6 \%$ were residing in rural areas, and $82.9 \%$ were attending at non-medical faculties. Most of the students reported wearing masks ( $79.8 \%$ always and $17.5 \%$ sometimes), using detergents $(81.5 \%$ always and $13.4 \%$ sometimes), and applying social distancing ( $77.5 \%$ always and $20.6 \%$ sometimes) (Table 1).

About $41.1 \%$ of the studied Saudi university students reported depression symptoms (31.7\% mild to moderate and $9.4 \%$ severe to very severe), $26.9 \%$ reported anxiety symptoms (15.8\% mild to moderate and $11.1 \%$ severe to very severe), and $22.4 \%$ reported stress symptoms ( $15.2 \%$ mild to moderate and $7.2 \%$ severe to very severe) (Table 2).

Several factors were associated with depression, anxiety, and stress symptoms. Of these factors, having a friend or relative infected with COVID-19 was associated with depression (OR 1.95, 95\% CI: 1.44-263) and anxiety (OR 1.98, 95\% CI: 1.44-2.72). The same psychological impacts were detected among those with a friend or relative who died from the COVID-19; depression (OR 1.86, 95\% CI: 1.07-3.23) and anxiety (OR 1.95, 95\% CI: 1.11-3.42). Watching/reading COVID-19 news [?] 2 hours/day was associated with depression, anxiety, and stress with OR (95\% CI) of 1.50 (1.04-2.16), 1.88 (1.29-2.76), and 1.50 (1.00-2.52), respectively. Besides, lack of perceived emotional support from family, society, and university was significantly related to all studied forms of psychological problems (Table 3).

\section{Discussion:}

The goal of this study was to evaluate the psychological conditions of university students during the COVID19 pandemic and explore factors influencing their psychological problems. This study indicated that $41.1 \%$ of 
university students at Umm AlQura University in Saudi Arabia were afflicted with symptoms of depression, $26.9 \%$ with anxiety, and $22.4 \%$ with stress.

Previous studies have suggested that the COVID-19 pandemic had profound negative psychological impacts on the general population as well as students(16). A study from Jordan assessed the prevalence of depression using the Patient Health Questionnaire and anxiety using Generalized Anxiety Disorder-7 among 1165 university students and showed that more than $60 \%$ of the surveyed students had moderate to severe depression and more than $45 \%$ had moderate to severe anxiety (6). Yet, it is difficult to compare their results with those of the current study because the authors used a convenience sampling approach that favors the inclusion of students with psychological problems in addition to using a different tool to assess depression and anxiety. In Spain, a total of 2530 members of the University of Valladolid were surveyed online for their psychological conditions using the DASS-21. The results showed that the prevalence of any degree of depression, anxiety, and stress was as follows: $48.1 \%, 35.2 \%$, and $40.3 \%$ while the prevalence of the moderate to severe forms was as follows: $34.2 \%, 21.3 \%$, and $28.1 \%$, respectively(13). The higher rates of all psychological conditions compared with ours, despite using the same study design and evaluation methods, could be explained by the fact that Spain was among the most affected countries worldwide in terms of the COVID-19 cases, deaths, and economic losses $(2,17)$.

It could be predicted that the quarantine measures and the state of anticipation about the academic progress during the COVID-19 pandemic may have harmed the students' mental and psychological health. A longitudinal study on 555 university students in China revealed increases in symptoms of anxiety and depression after two weeks of quarantine(10). Besides, the new learning environment that is based completely on online education may be addressed differently among students with various psychological reflections(7). Moreover, the students' psychological affection may have been related to stressors associated with social and physical distancing measures, infection fear, and boredom (18). It is not surprising that anxiety disorders are more likely to occur and worsen in the absence of interpersonal communication(19). A study conducted in Saudi Arabia on medical students claimed that being detached from friends was a major cause of anxiety (8). Our findings and similar studies can recommend the importance of providing urgent psychological services to university students to mitigate the psychological impacts of the COVID-19 pandemic.

We also highlighted the role played by other stressors in the students' psychological instability during the current COVID-19 pandemic. For example, the current study illustrated that having a relative or a friend infected with or died from the COVID-19 was associated with an increased level of depression and anxiety and this was consistent with previous literature(11,20). Watching COVID-19 news for long times per day was associated with depression, anxiety, and stress. As a consequence of the current pandemic, many people turn to social media outlets to connect with others and to express their feelings about the pandemic (21). Although media is considered a good source of information about safety precautions and prevention strategies, excessive description of COVID-19 news can create a sense of panic among vulnerable individuals. Social media and uncurious netizens may also be a source of fake scary information (20,22). This finding should raise the attention of mental health professionals to advise the public for a wise watching of the news and to cautiously use social media and telecommunication websites.

Moreover, the current study showed that students who reported lack of sleep had more stress and anxiety. Sleep disturbances are a stand-alone risk factor for psychological consequences. Appropriate treatment of sleep disturbances is always vital and reduces symptoms of psychiatric disorders (23). Recognizing and treating such disorders are particularly important during stressful times (24).

Furthermore, students who did not receive emotional support from their families, societies, and universitywere more likely to experience psychological problems. The current COVID-19 pandemic is considered an inexperienced crisis that affected the mental health of the exposed people and requires psychological support. A study on medical students from China showed that social support correlated negatively with their level of anxiety(11). One study discussed the need for providing mental healthcare services to students to alleviate their psychological disturbances (25). We should, therefore, there is a need to pay greater attention to the mental health of university students and actively provide them with psychological support and counseling. 
This study carried many strengths such as investigating, for the first time, the psychological conditions among a large cohort of university students in Saudi Arabia and using a validated tool to measure their psychological problems. However, the study has some limitations that should be addressed. First, the crosssectional design of this study cannot imply causality, and the baseline psychological conditions before the COVID-19 pandemic could not be assessed. Therefore, we cannot conclude that the COVID-19 pandemic was the only reason to provoke such psychological disturbances. Second, investigating one university in Saudi Arabia maybe not representative of the rest of the universities in the country. Third, the online approach of data collection could carry a potential possibility of non-response bias (26). To minimize the risk of this bias, we sent the questionnaire through all the possible means of communication with students of Umm AlQura University. We made the online questionnaire available for participation for a week and extended its availability for another week while sending reminders to students and encouraging them to share the questionnaire by sending it to their colleagues.

In conclusion, this study showed that students at Umm AlQura University suffered psychological problems during the COVID-19 pandemic. These problems were associated with related infection or death of a family member or relative, excessive following of news, lack of emotional support from the family, society, and the university. Our findings can be used to articulate psychological interventions to improve mental health and psychological resilience during the COVID-19 pandemic. It is warranted for universities to have a role in helping students respond to the pandemic in a healthier psychological performance.

Conflict of interest : the authors declare no competing interests.

Author Contributions: ZM and AA drafted the manuscript and substantially revised it, under supervision of AE. All authors have read and agreed to the published version of the manuscript.

Acknowledgment: The authors acknowledge the participated students

Funding: no funding source

\section{References:}

1. Wang C, Zhao H. The Impact of COVID-19 on Anxiety in Chinese University Students. Front Psychol. 2020;11:1168-.

2. World health organization. Coronavirus disease (COVID-19). Situation report-174. . 2020.

3. Yezli S, Khan A. COVID-19 social distancing in the Kingdom of Saudi Arabia: Bold measures in the face of political, economic, social and religious challenges. Travel medicine and infectious disease. 2020:101692.

4. Atique S, Itumalla R. Hajj in the Time of COVID-19. Infect Dis Health. 2020;25(3):219-21.

5. Sahu P. Closure of Universities Due to Coronavirus Disease 2019 (COVID-19): Impact on Education and Mental Health of Students and Academic Staff. Cureus. 2020;12(4):e7541-e.

6. Naser AY, Dahmash EZ. Mental health status of the general population, healthcare professionals, and university students during 2019 coronavirus disease outbreak in Jordan: A cross-sectional study. 2020:e01730.

7. Ozamiz-Etxebarria N, Dosil-Santamaria M. Stress, anxiety, and depression levels in the initial stage of the COVID-19 outbreak in a population sample in the northern Spain. 2020;36(4):e00054020.

8. Meo SA, Abukhalaf AA, Alomar AA, Sattar K, Klonoff DC. COVID-19 Pandemic: Impact of Quarantine on Medical Students' Mental Wellbeing and Learning Behaviors. Pak J Med Sci. 2020;36(COVID19-S4):S43S8.

9. Huckins JF, daSilva AW. Mental Health and Behavior of College Students During the Early Phases of the COVID-19 Pandemic: Longitudinal Smartphone and Ecological Momentary Assessment Study. 2020;22(6):e20185. 
10. Li HY, Cao H, Leung DYP, Mak YW. The Psychological Impacts of a COVID-19 Outbreak on College Students in China: A Longitudinal Study. Int J Environ Res Public Health. 2020;17(11):3933.

11. Cao W, Fang Z, Hou G, Han M, Xu X, Dong J, et al. The psychological impact of the COVID-19 epidemic on college students in China. Psychiatry research. 2020;287:112934.

12. Tang W, Hu T, Hu B, Jin C, Wang G, Xie C, et al. Prevalence and correlates of PTSD and depressive symptoms one month after the outbreak of the COVID-19 epidemic in a sample of home-quarantined Chinese university students. Journal of affective disorders. 2020;274:1-7.

13. Odriozola-González P, Planchuelo-Gómez Á, Irurtia MJ, de Luis-García R. Psychological effects of the COVID-19 outbreak and lockdown among students and workers of a Spanish university. Psychiatry research. 2020;290:113108-.

14. Lovibond P. and P. Lovibond. Manual for the Depression, Anxiety and Stress Scales (2nd ed). Sydney, Australia: Psychology Foundation. 1995.

15. Ali AM, Ahmed A, Sharaf A, Kawakami N, Abdeldayem SM, Green J. The Arabic Version of The Depression Anxiety Stress Scale-21: Cumulative scaling and discriminant-validation testing. Asian J Psychiatr. 2017;30:56-8.

16. Holmes EA, O'Connor RC, Perry VH, Tracey I, Wessely S, Arseneault L, et al. Multidisciplinary research priorities for the COVID-19 pandemic: a call for action for mental health science. The lancet Psychiatry. 2020;7(6):547-60.

17. Trias-Llimós S, Bilal U. Impact of the COVID-19 pandemic on life expectancy in Madrid (Spain). Journal of public health (Oxford, England). 2020.

18. Brooks SK, Webster RK, Smith LE, Woodland L, Wessely S, Greenberg N, et al. The psychological impact of quarantine and how to reduce it: rapid review of the evidence. Lancet (London, England). 2020;395(10227):912-20.

19. Xiao C. A Novel Approach of Consultation on 2019 Novel Coronavirus (COVID-19)-Related Psychological and Mental Problems: Structured Letter Therapy. Psychiatry Investig. 2020;17(2):175-6.

20. Sahoo S, Rani S, Parveen S, Pal Singh A, Mehra A, Chakrabarti S, et al. Self-harm and COVID-19 Pandemic: An emerging concern - A report of 2 cases from India. Asian J Psychiatr. 2020;51:102104-.

21. Nabity-Grover T, Cheung CMK, Thatcher JB. Inside out and outside in: How the COVID-19 pandemic affects self-disclosure on social media. Int J Inf Manage. 2020:102188.

22. Ayittey FK, Ayittey MK, Chiwero NB. Economic impacts of Wuhan 2019-nCoV on China and the world. 2020;92(5):473-5.

23. Killgore WDS, Cloonan SA, Taylor EC, Fernandez F, Grandner MA, Dailey NS. Suicidal ideation during the COVID-19 pandemic: The role of insomnia. Psychiatry research. 2020;290:113134-.

24. Sher L. COVID-19, anxiety, sleep disturbances and suicide. Sleep Med. 2020;70:124-.

25. Zhai Y, Du X. Addressing collegiate mental health amid COVID-19 pandemic. Psychiatry research. 2020;288:113003-.

26. Arafa AE, Anzengruber F, Mostafa AM, Navarini AA. Perspectives of online surveys in dermatology. Journal of the European Academy of Dermatology and Venereology : JEADV. 2019;33(3):511-20.

Table 1: Sociodemographic characteristics of Saudi university students and their attitudes towards the COVID-19 pandemic

\begin{tabular}{lll}
\hline Characteristics & Characteristics & Overall $\mathrm{n}=936(\%)$ \\
\hline Age (years) & $<23$ & 57.8
\end{tabular}




\begin{tabular}{|c|c|c|}
\hline Characteristics & Characteristics & Overall $n=936(\%)$ \\
\hline & {$[?] 23$} & 42.2 \\
\hline \multirow{2}{*}{ Sex } & Men & 43.6 \\
\hline & Women & 56.4 \\
\hline \multirow[t]{2}{*}{ Residence } & Urban & 43.4 \\
\hline & Rural & 56.6 \\
\hline \multirow[t]{2}{*}{ Discipline } & Medical & 17.1 \\
\hline & Non-medical & 82.9 \\
\hline \multirow{3}{*}{$\begin{array}{l}\text { Having a friend or relative } \\
\text { infected with COVID-19 }\end{array}$} & Yes & 24.4 \\
\hline & No & 66.1 \\
\hline & Not sure & 9.5 \\
\hline \multirow{3}{*}{$\begin{array}{l}\text { Having a friend or relative died } \\
\text { of COVID-19 }\end{array}$} & Yes & 5.8 \\
\hline & No & 91.1 \\
\hline & Not sure & 3.1 \\
\hline \multirow[t]{3}{*}{ Wearing masks } & Always & 79.8 \\
\hline & Sometimes & 17.5 \\
\hline & Never & 2.7 \\
\hline \multirow[t]{3}{*}{ Using detergents } & Always & 81.5 \\
\hline & Sometimes & 13.4 \\
\hline & Never & 5.1 \\
\hline \multirow[t]{3}{*}{ Applying social distancing } & Always & 77.5 \\
\hline & Sometimes & 20.6 \\
\hline & Never & 1.9 \\
\hline \multirow{3}{*}{$\begin{array}{l}\text { Watching/reading COVID-19 } \\
\text { news (hours/day) }\end{array}$} & $<2$ & 85.6 \\
\hline & $2-4$ & 10.1 \\
\hline & $>4$ & 4.3 \\
\hline \multirow[t]{2}{*}{ Sleeping (hours/day) } & $<6$ & 18.3 \\
\hline & {$[?] 6$} & 81.7 \\
\hline \multirow[t]{2}{*}{ Emotional support from family } & Yes & 91.9 \\
\hline & No & 8.1 \\
\hline \multirow[t]{2}{*}{ Emotional support from society } & Yes & 76.2 \\
\hline & No & 23.8 \\
\hline \multirow{2}{*}{$\begin{array}{l}\text { Emotional support from the } \\
\text { university }\end{array}$} & Yes & 74.4 \\
\hline & No & 25.6 \\
\hline
\end{tabular}

Table 2: Prevalence of depression, anxiety and stress among Saudi university students during the COVID-19 pandemic

\begin{tabular}{lll}
\hline Psychological features & Psychological features & Overall $\mathrm{n}=936(\%)$ \\
\hline Depression & Normal & 58.9 \\
& Mild to moderate & 31.7 \\
Anxiety & Severe to very severe & 9.4 \\
& Normal & 73.1 \\
Stress & Mild to moderate & 15.8 \\
& Severe to very severe & 11.1 \\
& Normal & 77.6
\end{tabular}




\begin{tabular}{lll}
\hline Psychological features & Psychological features & Overall $\mathrm{n}=936(\%)$ \\
\hline & Mild to moderate & 15.2 \\
& Severe to very severe & 7.2 \\
\hline
\end{tabular}

\begin{tabular}{|c|c|c|c|c|}
\hline Characteristics & Characteristics & Depression $(\mathrm{n}=385)$ & Depression $(\mathrm{n}=385)$ & Anxiety $(\mathrm{n}=252)$ \\
\hline & & $\%$ & OR $(95 \% \mathrm{CI})$ & $\%$ \\
\hline \multirow{2}{*}{ Age } & $<23$ years & 43.4 & $1.25(0.96-1.64)$ & 27.9 \\
\hline & {$[?] 23$ years } & 38.0 & 1 & 25.6 \\
\hline \multirow[t]{2}{*}{ Sex } & Men & 40.9 & $0.99(0.76-1.28)$ & 25.0 \\
\hline & Women & 41.3 & 1 & 28.4 \\
\hline \multirow[t]{2}{*}{ Residence } & Urban & 40.6 & $0.97(0.74-1.26)$ & 27.8 \\
\hline & Rural & 41.5 & 1 & 26.2 \\
\hline \multirow[t]{2}{*}{ Discipline } & Medical & 45.6 & $1.25(0.87-1.76)$ & 30.6 \\
\hline & Non-medical & 40.2 & 1 & 26.2 \\
\hline \multirow{2}{*}{ Friend or relative with COVID-19 } & Yes & 53.5 & $1.95(1.44-2.63)$ & 37.7 \\
\hline & No or not sure & 37.1 & 1 & 23.4 \\
\hline \multirow{2}{*}{ Friend or relative died of COVID-19 } & Yes & 55.6 & $1.86(1.07-3.23)$ & 40.7 \\
\hline & No or not sure & 40.2 & 1 & 26.1 \\
\hline \multirow[t]{2}{*}{ Wearing masks } & Sometimes/Never & 43.9 & $1.15(0.84-1.59)$ & 31.7 \\
\hline & Always & 40.4 & 1 & 25.7 \\
\hline \multirow[t]{2}{*}{ Using detergents } & Sometimes/Never & 52.0 & $1.72(1.23-2.40)$ & 34.1 \\
\hline & Always & 38.7 & 1 & 25.3 \\
\hline \multirow[t]{2}{*}{ Applying social distancing } & Sometimes/Never & 43.6 & $1.14(0.84-1.55)$ & 27.0 \\
\hline & Always & 40.4 & 1 & 26.9 \\
\hline \multirow[t]{2}{*}{ Watching/reading COVID-19 news } & {$[?] 2$ hours/day } & 49.6 & $1.50(1.04-2.16)$ & 38.5 \\
\hline & $<2$ hours/day & 39.7 & 1 & 25.0 \\
\hline \multirow[t]{2}{*}{ Sleeping hours } & $<6$ hours/day & 47.4 & $1.37(0.98-1.91)$ & 39.8 \\
\hline & {$[?] 6$ hours/day } & 39.7 & 1 & 24.1 \\
\hline \multirow[t]{2}{*}{ Emotional support from family } & No & 57.9 & $2.09(1.30-3.37)$ & 42.1 \\
\hline & Yes & 39.7 & 1 & 25.6 \\
\hline \multirow[t]{2}{*}{ Emotional support from society } & No & 52.9 & $1.88(1.39-2.54)$ & 34.1 \\
\hline & Yes & 37.4 & 1 & 24.7 \\
\hline \multirow[t]{2}{*}{ Emotional support from university } & No & 56.1 & $2.28(1.69-3.08)$ & 37.7 \\
\hline & Yes & 35.9 & 1 & 23.2 \\
\hline
\end{tabular}

Table 3: Odds ratios and confidence intervals of the associations with depression, anxiety, and stress among Saudi university students during the COVID-19 pandemic 